\title{
Climate Data Management Systems: status of implementation in developing countries
}

\author{
Denis Stuber $^{1, *}$, Albert Mhanda ${ }^{2}$, Christiana Lefebvre ${ }^{3}$ \\ ${ }^{1}$ Climatology Directorate, Meteo France, 31057 Toulouse cedex 1, France \\ ${ }^{2}$ Zimbabwe Climate Change Office, Cnr Central Ave/4th Street, Harare, Zimbabwe \\ ${ }^{3}$ Deutscher Wetterdienst (DWD), Marine Met. Monitoring Centre, 20359 Hamburg, Germany
}

\begin{abstract}
In the mid-1980s, the World Meteorological Organization (WMO) began a major initiative, the CLICOM (CLImate COMputing) project, to support the storage and management of climatological data, particularly in developing countries. The CLICOM project was characterised by a common software shared by almost 100 countries. In 2010 the picture has completely changed. It is no longer one but several Climate Data Management Systems (CDMSs) that are now available to National Meteorological and Hydrological Services (NMHSs). New CDMSs fall into a number of categories whose technical solutions, functions and commercial policies differ. We discuss the methods used to distribute these CDMSs as well as their worldwide installation, and we propose a way to assess their implementation.
\end{abstract}

KEY WORDS: Climate Data Management Systems $\cdot$ CDMS $\cdot$ WMO support $\cdot$ Training $\cdot$ Developing countries

Resale or republication not permitted without written consent of the publisher

\section{INTRODUCTION}

Computer technologies are essential tools for processing climatological data and storing the huge amount of meteorological measurements and derived information that a National Meteorological and Hydrological Service (NMHS) should offer to its users. Consequently the World Meteorological Organization (WMO) has been supporting the implementation of Climate Data Management Systems (CDMSs) in developing countries for $>20$ yr now.

In the present paper we describe the policies adopted by the WMO to assist developing countries in managing their climatological data and metadata, and we discuss the different CDMSs and their modes of distribution.

We will look at the installation of so-called 'new CDMSs' (post-2000; see Section 2 below) in NMHSs, particularly in developing countries and least-developed countries. We will also attempt to identify the successful (i.e. operational) CDMSs.

\section{HISTORY AND POLICIES}

The year 2000 was a turning point in the use of CDMSs in developing countries. Before 2000, interna- tional efforts concentrated on a common system named CLICOM (CLImate COMputing); after 2000 several CDMSs emerged, which we will call 'new CDMSs' in the present paper, that marked the beginning of (1) a choice of CDMSs for the NMHSs, and (2) commercial and technical competition for the CDMs suppliers.

\subsection{0-2000: implementation of CLICOM}

In the late 1980s, with their increasing popularity, personal computers (PCs) started to be present in climatology offices of developing countries. Under an initiative of the WMO, the CLICOM project was founded, and resulted in the implementation of the CLICOM CDMS tool in almost 100 countries in the late 1990s.

CLICOM was undoubtedly a success both in terms of international participation in training, equipment and facilities, and in terms of professionalism and robustness of the software. The CLICOM software (whose development and maintenance was provided by the National Oceanic and Atmospheric Administration) was identical for all the NMHSs that used it, and offered (still offers, for $>20$ NMHSs) the essential climatological functions of acquisition, storage, preserva- 
tion and control of data, plus data access and various products.

Even though CLICOM continued to be installed after the year 2000, the software did not meet the newer technological standards, especially in terms of the database engine (DataEase) and operating system (MS-DOS). The last version of CLICOM, v. 3.1, was released in October 1999. As no-one took on the considerable task of upgrading CLICOM, new CDMSs emerged, developed by NMHSs, private companies or a combination of both.

\subsection{0-2010: systems plurality}

Concerned with finding a solution for numerous developing-country NMHSs that were equipped with CLICOM but would have to migrate in the short term to a new-generation CDMS, the WMO contacted its members and organised several meetings on this matter (see WMO 1997, 1998, 1999).

The WMO called for worldwide CDMS candidates to be shared by its members (see WMO 2000a, 2002). Two questionnaires were sent to members to find out which CDMS functions they wanted and which countries were prepared to offer their CDMS to share with other members. The replies were used to decide which functional requirements were needed in future WMO CDMSs, and which, of those CDMSs offered, met these requirements sufficiently well to merit being part of the next in-depth testing phase for possible future use in the WMO member countries.

Several NMHSs proposed that their CDMSs be shared. In May 2002, the WMO conducted a complete evaluation of several CDMSs, testing their functions and analysing their strengths and weaknesses. The current picture is no longer 'one system for all', but several CDMSs that differ in terms of technical solutions, functions, as well as development and maintenance processes.

\subsection{CDMSs now in use}

Seven distributed CDMSs are known to be in use in developing countries: CLDB, CLICOM, CLIDATA, CLIMSOFT, CLISYS, CLIWARE and JCDMS (Table 1).

It is likely that this list will increase because the Australian Bureau of Meteorology is currently developing a CDMS for Pacific countries. Other NMHSs or private companies may also propose new CDMSs soon, e.g. the Morocco meteorological service has recently proposed to supply its CDMS to the meteorological community.

Of the 7 CDMSs in use, 5 were part of the WMO evaluation in 2002: CLIDATA, CLIMSOFT, CLISYS, CLIWARE and JCDMS.

Some developing-country climatological departments are using systems other than the 7 that we have listed here. Several have developed their own CDMS, some of which are modern, high-performance systems with various climatological functions, while others use simple spreadsheets or have no computer at all. The present paper focuses on known CDMSs that are distributed to NMHSs.

\subsection{Suppliers}

Without taking into account the CLICOM system, which is no longer maintained, CDMS suppliers can be divided into 4 categories: (1) CDMSs that have been completely developed by a NMHS. That is the case with CLIWARE, maintained by Roshydromet in Russia, and JCDMS, by the Jordan Meteorological Department. (2) CDMSs that have been developed by a NMHS along with a private company. CLIDATA (Czech Hydrometeorological Institute) and CLISYS (Meteo France) belong to this category. In most cases the private companies (in these 2 cases Ataco and Meteo France International, respectively) assume responsibility for maintenance, installation and upgrade. (3) CDMSs that are a fully commercial product without links to NMHSs. The only example up to now is the CLDB system of MicroStep-MIS, which also provides the development, maintenance and training. (4) Finally, there is the particular approach of the CLIMSOFT project. Under the sponsorship of the UK Met Office, the project involves African developers located in Zimbabwe, Kenya and Guinea and aims to

Table 1. List of available Climate Data Management Systems (CDMSs), their licence policies and suppliers. NMHS: National Meteorological and Hydrological Service

\begin{tabular}{|c|c|c|}
\hline CDMS & Licence & Supplier \\
\hline CLDB & Under licence & MicroStep-MIS, a private company from Slovakia \\
\hline CLICOM $^{a}$ & Free software & WMO \\
\hline CLIDATA & Under licence & $\begin{array}{l}\text { Ataco Ltd. and Czech Hydrometeorological } \\
\text { Institute }\end{array}$ \\
\hline CLIMSOFT & Free software & $\begin{array}{l}\text { Developed under a UK Met Office initiative by an } \\
\text { African team of } 3 \text { persons located in Zimbabwe, } \\
\text { Kenya and Guinea }\end{array}$ \\
\hline CLISYS & Under licence & Meteo France and Meteo France International \\
\hline CLIWARE & Free software & Roshydromet of Russia \\
\hline JCDMS & Free software & Jordan Meteorological Department \\
\hline
\end{tabular}


provide a free and easy-to-use CDMS for developing countries.

\section{DISTRIBUTION AND TRAINING}

Stating the gradual 'death' of the CLICOM software, WMO launched an international campaign about the new CDMSs in order to ensure the continuity of NMHSs' data-management capacity.

\subsection{6-2002: CLICOM implementation}

The CLICOM system was mainly implemented through the WMO Voluntary Cooperation Programme (VCP) that consisted of 1 or 2 phases involving installation and training by a CLICOM expert on site for each country in question. Regional workshops were also organised to consolidate training, answer difficulties, or assist in system upgrades (see WMO 2000b).

According to the WMO, during 1994-2002, there were 86 VCP operations working on CLICOM and climatological activities. In terms of working status, of those 86 operations, 58 were considered satisfactory, 24 not fully satisfactory, and 4 out of service (WMO 2003).

\subsection{3-2004: information campaign}

Before starting CLICOM replacement, WMO initiated a large diffusion of information on the new CDMSs, especially targeting the developing world. Regional meetings were organised that focused on data rescue and on the new CDMSs available.

These meetings took place in Ecuador (March 2003), Kyrgyzstan (April 2003), Niger (September 2003), Malaysia (October 2003), Laos (November 2003), Cameroon (July 2004), Lebanon (September 2004) and Australia (December 2004).

\subsection{3 to the present: installation/implementation of new CDMSs}

In 2003 the first installations were started using different methods depending on the CDMS, the recipient country, or the supplier.

\subsubsection{Workshops}

This method has been used by the WMO especially for CLIMSOFT, and consists of workshops for repre- sentatives of NMHSs for a period of 1 or $2 \mathrm{wk}$. The objective here is to adequately train each NMHS representative (i.e. training the trainers) so that when they return to their own offices they can implement the system and train the rest of the staff. During these workshops, trainees have usually been given a laptop to take back to their countries.

Five such workshops have been organised for a total of 52 country appearances, including 41 developing countries, which in turn included 25 least-developed countries.

- Fiji, September 2005, for the Pacific region. 10 NMHSs took part: Cook Islands, Fiji, Kiribati, Papua New Guinea, Niue, Samoa, Solomon Islands, Tonga, Tuvalu, and Vanuatu.

- Trinidad and Tobago, May 2006, for the Caribbean.13 NMHSs: Anguilla, Bahamas, Belize, British Virgin Islands, Cayman Islands, Dominica, Grenada, Montserrat, Netherlands Antilles and Aruba, St. Kitts and Nevis, St. Lucia, St. Vincent and the Grenadines, and Turks and Caicos.

- Rwanda, September 2006, for Eastern and Southern Africa. 10 NMHSs: Burundi, Lesotho, Malawi, Namibia, Rwanda, Seychelles, Swaziland, Tanzania, Uganda, and Zambia.

- Congo, April 2007, for Central Africa. 8 NMHSs: Angola, Cameroon, Central African Republic, Chad, Congo-Brazzaville, Democratic Republic of Congo, Gabon, and Sao Tome and Principe.

- Vietnam, November 2007, for Southeast Asia. 11 NMHSs: Bhutan, Cambodia, Fiji, Laos, Maldives, Myanmar, Nepal, Sri Lanka, Thailand, Democratic Republic of Timor-Leste, and Vietnam.

Workshops appear to be adequate solutions for sharing experiences, and for encouraging synergy between users as well as future collaboration and partnerships. They are also economical in terms of trainer resources. But workshops also have disadvantages such as: (1) only 1 employee of the NMHS is trained and the success of the implementation will depend on that person, and (2) no time is devoted to the integration of the system into the real world, i.e. the NMHS premises. It is very difficult to assess the real implementation of the software in the NMHS because this is only done after the workshop.

\subsubsection{WMO Voluntary Cooperation Programmes or bilateral cooperation}

During the CLICOM period, as many as 86 VCP operations took place, compared to only 4 during the period 2003 to 2007. These 4 were for CLISYS (Madagascar), CLIWARE (Kazakhstan) and CLIDATA (Ghana, Macedonia) (WMO 2003, 2004, 2005, 2006b, 2007, 2008). 
Some CLIDATA systems have been implemented through bilateral cooperation: in the Dominican Republic, Ethiopia, Latvia, Lithuania, and Serbia. JCDMS has been installed through bilateral cooperation in Syria by the Jordan Meteorological Department.

From 1988 to 2007, VCPs supported 49\% of the demand for CDMSs and climatological activities. The fact that there remains $51 \%$ that were not selected by VCPs is indicative of the demand in terms of CDMSs and climatological activities.

\subsubsection{Funding by regional project or regional organisation}

These distribution methods are characterised by projects that include several NMHSs and that are conducted by WMO regional associations (RAs) using one particular CDMS.

Two RAs have followed this method, where CDMS installation and training were done first in Regional Centre offices and then spread out to the NMHSs that were part of the project.

One case is that of the Caribbean region, which has benefited from a WMO project called 'Preparedness to climate variability and global change in small islands' funded by the government of Finland. Thanks to this project, Antigua and Barbuda, Barbados, Cuba, Haiti, Jamaica, and Trinidad and Tobago have received CLIDATA systems and training through the Caribbean Institute for Meteorology and Hydrology (CIMH).

The second case is one coordinated by the Agrometeorology and Hydrology Regional Centre (AGRHYMET), the specialised institute of the Permanent Interstate Committee for Drought Control in the Sahel (CILSS), composed of 9 member states. All CILSS members are now equipped with CLIDATA: Cape Verde, Gambia, Guinea-Bissau, Burkina Faso, Mali, Mauritania, Niger, Senegal, and Chad. This project also includes 5 countries of the Economic Community of West African States (ECOWAS): Benin, Ivory Coast, Guinea, Togo, and Ghana.

An important advantage of a regional project is that follow-up, training, and equipment maintenance are integrated into the project most of the time, which ensures better continuity.

\subsubsection{NMHS purchase}

The last method is one where a NMHS purchases a CDMS from the private market. Twenty NMHSs have chosen this route, 12 of which are considered to be developing countries and 2 as least-developed countries.
- CLDB: Bahrain, Kyrgyzstan, Latvia, Malaysia, Macedonia, Oman, Saudi Arabia, Serbia, United Arab Emirates, and Yemen.

- CLIDATA: Bosnia, Estonia, Montenegro, and Namibia. - CLISYS: Egypt, India, Indonesia, Libya, Qatar, and Swaziland.

The implementation costs might be prohibitive for some countries. But on the other hand this method can fulfil the exact requirements, software and training needs of an NMHS.

\subsubsection{Summary}

Fig. 1 displays the number of developing countries and least-developed countries that have installed new CDMS through the various different routes. In percentage terms, it shows that $59 \%$ of developing countries and $82 \%$ of least-developed countries have benefited from new CDMSs, and that $53 \%$ of new-CDMS installations have been undertaken through workshops.

\section{INSTALLATION STATUS IN 2011}

\subsection{Sources of information}

It would be unrealistic to say that the data in this section represent strict reality. What can be said is that most of the information has been gathered then merged and verified to be as close as possible to the current status in each NMHS. For nearly $20 \%$ of developing countries, however, no information is available on the CDMS tools in use.

All data were obtained from: (1) the WMO secretariat and publications from the WMO Technical Cooperation Programme; (2) the WMO Commission for

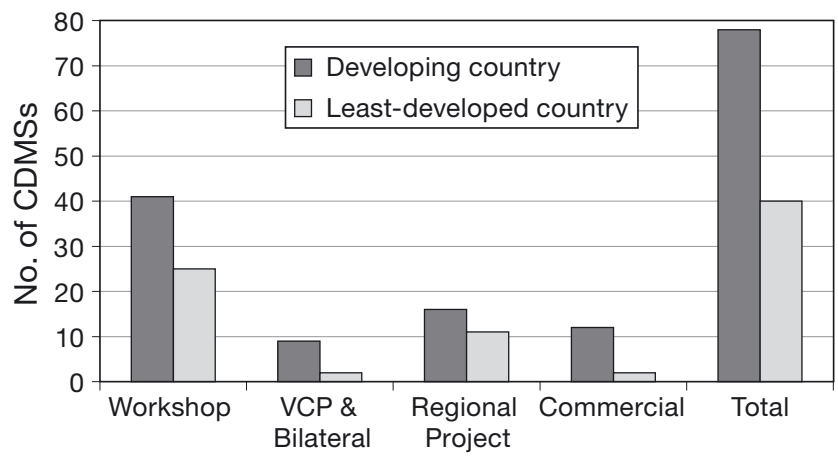

Fig. 1. Number of installations of new Climate Data Management Systems (CDMSs) in developing countries and leastdeveloped countries per method of distribution. VCP \& Bilateral: WMO Voluntary Cooperation Programme or bilateral cooperation 
Climatology $(\mathrm{CCl})$ meetings on CDMSs, especially the $\mathrm{CCl}$ Expert Team on Climate Data Management including Metadata (OPAG 1.1); (3) NMHSs having strong links with CDMS-development companies: Czech Republic, France, Russia, and Australia; and (4) the Association of Hydro-Meteorological Equipment Industry (HMEI), which includes some CDMSdevelopment companies, i.e. MicroStep-MIS, Ataco, and Meteo France International.

Classifying countries as developing countries and least-developed countries is also subject to discussion. We use the classifications according to the International Monetary Fund and the World Bank (e.g. 52 developing countries in Africa, 33 of which are considered least-developed countries) (Table 2).

\subsection{1 assessment of installation}

\subsubsection{Developing countries}

Fig. 2 displays the number of WMO members that are developing countries and least-developed countries who use 1 of the 7 distributed CDMSs. 'Locally developed' on the $x$-axis includes those using a CDMS developed locally, whether that means a CDMS with the latest technology, or data managed by simple flat files or spreadsheets; 'unknown' means that no CDMS information is available.

It appears that: (1) CLIMSOFT is the most installed software in developing countries: 39 installations that represent $29 \%$ of developing countries, and $45 \%$ of least-developed countries with 22 installations. But these figures are probably over-estimated, as most CLIMSOFT installations have been counted from workshops rather than real CDMS operational status. (2) Even now, 21 CLICOM systems (16\% of developing countries) are being used in the world and all of these are in developing countries. This could be even higher, considering that we do not have information for 25 developing coun-

Table 2. Number of developing countries and least-developed countries per WMO region

\begin{tabular}{|lcc|}
\hline WMO region & $\begin{array}{c}\text { Developing } \\
\text { countries }\end{array}$ & $\begin{array}{c}\text { Least-developed } \\
\text { countries }\end{array}$ \\
\hline I Africa & 52 & 33 \\
II Asia & 22 & 9 \\
III South America & 11 & 0 \\
IV North America, & 15 & 1 \\
$\quad$ Central America & & \\
$\quad$ and the Caribbean & 13 & 6 \\
V Southwest Pacific & 20 & 0 \\
VI Europe & 133 & 49 \\
Total & & \\
\hline
\end{tabular}

tries. Those NMHSs still using CLICOM will, in the coming years, have to migrate to a new CDMS.

\subsubsection{Regional distribution}

Fig. 3 shows the total number of developing countries per WMO region and the number of those that have received a new CDMS (CLDB, CLIDATA, CLIMSOFT, CLISYS, CLIWARE, JCDMS).

Fig. 4 shows, for each of the 6 WMO regions, the number of WMO member countries (including industralised countries) using each CDMS (CLICOM, CLDB, CLIDATA, CLIMSOFT, CLISYS, CLIWARE, JCDMS) and the number of developing countries and least-developed countries. Those using a locally developed system and

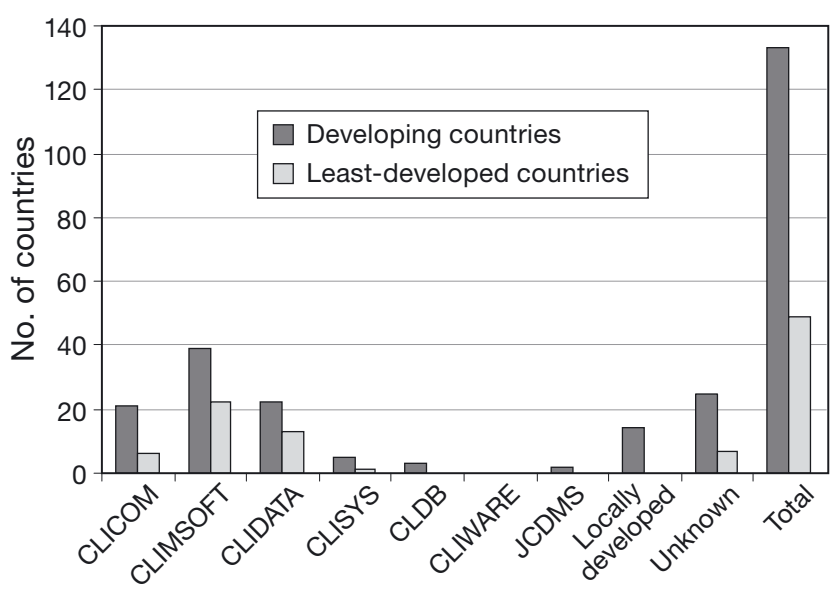

Fig. 2. Number of developing countries and least-developed countries using 1 of 7 Climate Data Management Systems (CDMSs), plus those that have developed a CDMS locally or for whom there is no information about CDMS use ('unknown')

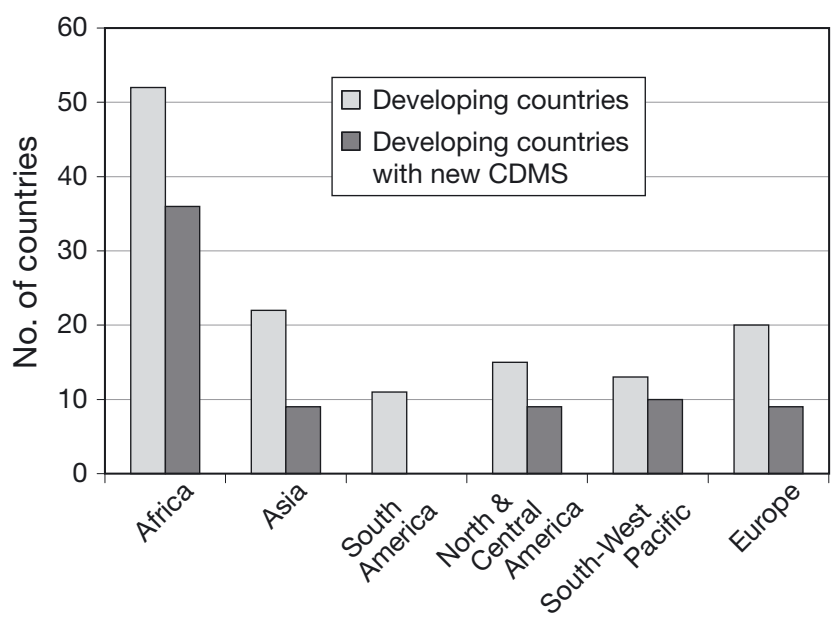

Fig. 3. Total number of developing countries per WMO region, and those using 1 of the 6 new Climate Data Management Systems (CDMSs) 

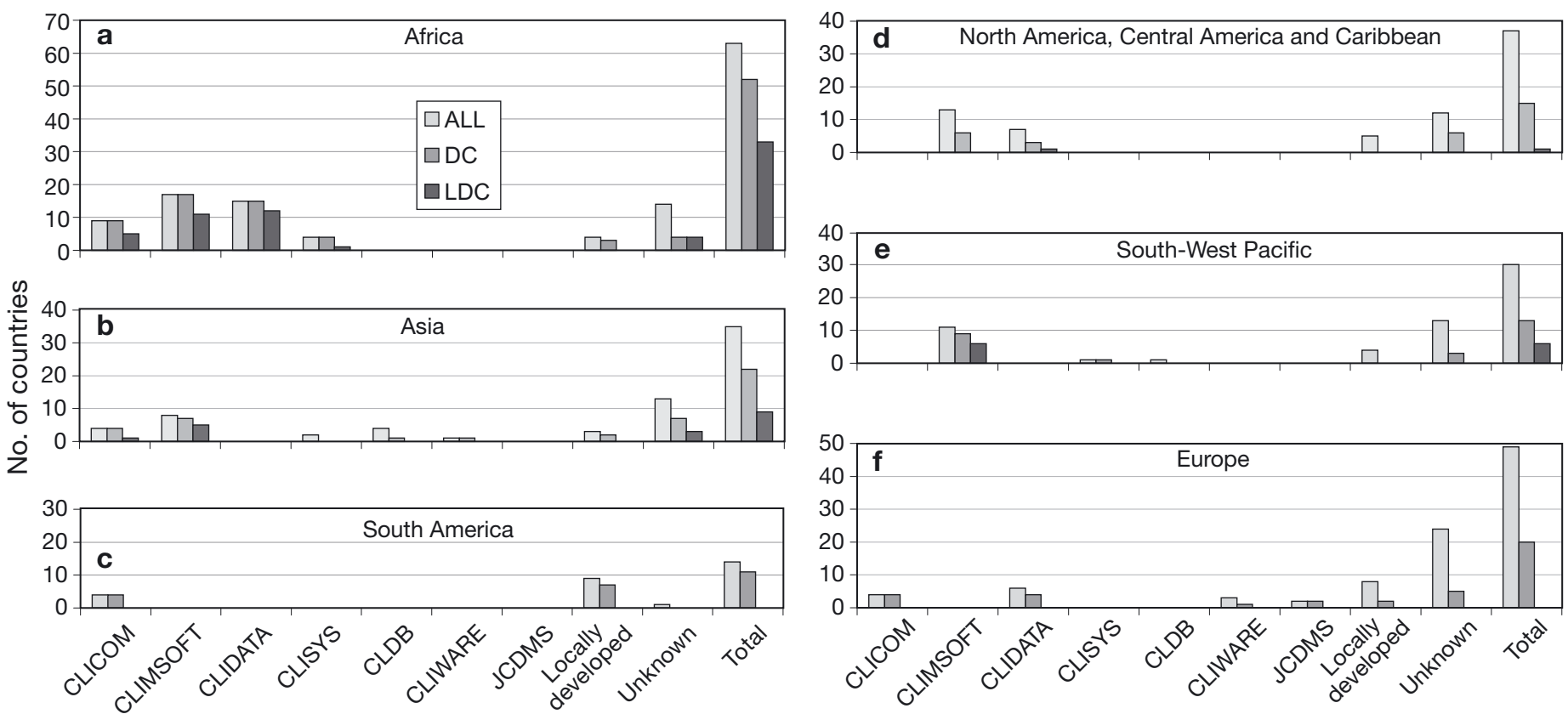

Fig. 4. Number of countries in the WMO regional association (a) I (Africa), (b) II (Asia), (c) III (South America), (d) IV (North America, Central America and Caribbean), (e) V (Southwest Pacific), (f) VI (Europe), using 1 of 7 Climate Data Management Systems (CDMSs), plus those that have developed a CDMS locally or for whom there is no information about CDMS use ('unknown'). ALL: all WMO members in this region; DC: developing countries; LDC: least-developed countries

those for which no CDMS information is available are also shown.

We note that: (1) 34 NMHSs from the developing world (including 5 least-developed countries) did not benefit from CLIMSOFT workshops or other installations of new CDMSs: 12 from RA I, 5 from RA II, 11 from RA III and 6 from RA VI. (2) Africa (RA I) is the WMO region with the highest number of new-CDMS installations, with 36 in developing countries, including 24 least-developed countries. Africa represents $51 \%$ of all new-CDMS installations. (3) South America (RA III) has no new-CDMS installations. Among the 14 developing countries of this region, 4 are running CLICOM and 7 have developed their CDMS locally. (4) Central America does not have any new-CDMS installations. All installations in North America, Central America and the Caribbean (RA IV) are concentrated on islands referred to by the United Nations term 'Small Island Developing States' (SIDS). (5) Most of the new CDMSs for the southwest Pacific (RA V) have been installed in SIDS.

\section{TENTATIVE ASSESSMENT OF IMPLEMENTATION}

Counting CDMS installations is relatively easy. One installation means that hardware and software are in place and the CDMS system is running. It also includes staff having been trained in its basic capabilities. Implementation represents a step beyond. Implementation assumes first that the CDMS has been installed but furthermore that the 'CDMS is being used on a regular and operational basis for the processing of real data observation to prepare a quality controlled data archive which is then being used to produce output for users' (WMO 1989, p. 2).

Assessing the status of CDMS implementation requires receiving concrete information from NMHSs. A questionnaire was created by a $\mathrm{CCl}$ Expert Team (WMO 2006a, 2009a, 2009b) and sent in May 2010 to all WMO members. The analysis of the answers, planned for the end of 2010, should provide an update for the data given in the present study and provide a better view of CDMS status: Who is using what? What are the needs? Who is in difficulty?

Meanwhile, an indicator to assess new-CDMS implementation has been explored. This is a way to evaluate whether data management in NMHSs has improved with the use of new CDMSs.

CLIMAT message analysis would seem to be a good candidate for such an indicator. CLIMAT messages are messages of monthly climatological data assembled at land-based meteorological surface observation sites. They have to be sent to data centres every month, and exchanged via the Global Telecommunication System (GTS) of the WMO. The correct transmission of these messages reflects the capacity of a NMHS to: (1) col- 
lect, on time, the data of its Regional Basic Climatological Network (RBCN), (2) compute monthly data, (3) code a CLIMAT message, and (4) transmit the CLIMAT message. The first 3 processes are generally part of a CDMS's functions.

The idea here was to compare the evolution of developing countries in producing their CLIMAT messages before and after receiving a new CDMS. It should be noted that some developing countries do not use their CDMSs to produce CLIMAT message but produce it manually. Nevertheless, evaluating manual CLIMAT messages could still indicate whether data management, in general, has improved or not. In this case it would give us an indication not of the CDMS itself, but of the capabilities of the NMHS organisation.

\subsection{Methodology}

Four different groups of NMHSs were all considered to be developing countries. The objective was to compute the percentage of CLIMAT messages that reached a WMO centre with a correct format in 2 time periods: 2000-2002 and 2006-2008. The time period 2000-2002 corresponds to an old generation of CDMSs, generally the CLICOM system. The time period 20062008 corresponds to new CDMSs.

Group 1, from the African WMO region (RA I), is composed of 9 NMHSs associated with AGRHYMET: Burkina Faso, Cape Verde, Chad, Gambia, Guinea-Bissau, Mali, Mauritania, Niger, and Senegal.

Group 2, also from RA I, is composed of 12 NMHSs not associated with AGRHYMET: Burundi, Comoros, Kenya, Lesotho, Madagascar, Malawi, Rwanda, Seychelles, Tanzania, Uganda, Zambia, and Zimbabwe.

Group 3, from the North and Central America and Caribbean WMO region (RA IV), is composed of 15 NMHSs: Anguilla, Bahamas, Belize, Dominica, Grenada, St. Kitts and Nevis, St. Lucia, St. Vincent and the Grenadines, Antigua and Barbuda, Barbados, Cuba, Dominican Republic, Haiti, Jamaica, and Trinidad and Tobago.

Group 4, from the Pacific WMO region (RA V), is composed of 9 NMHSs: Cook Islands, Fiji, Kiribati, Papua New Guinea, Samoa, Solomon Islands, Tonga, Tuvalu, and Vanuatu.

The German Meteorological Service (DWD) is (together with the Japan Meteorological Agency [JMA]) a Global Climate Observing System (GCOS) Surface Network (GSN) Monitoring Centre, in charge of the worldwide monitoring of CLIMAT messages, and has agreed to produce statistics for this specific question. DWD first extracted all stations belonging to the countries in Groups 1 to 4 from 'WMO No. 9, Volume A-Observing stations' that were indicated as being a CLIMAT reporting station. Then checks were performed on the monthly monitoring files of DWD (CLIMAT messages received at DWD up to the 21st day, 0:00 UTC, of the month), regarding only Section 1 of a CLIMAT message.

\subsection{Results and comments}

The results (Table 3 ) are very similar for Groups 1, 2, and 3, with an improvement of correct CLIMAT messages of +5.2 percentage points on average. However, the SIDS from the Pacific region show a drop of -15.1 percentage points.

According to this indicator, the installation of new CDMSs at NMHSs in Africa and the Caribbean region may have benefited the climatological activities of these NMHSs. On the other hand, for those from Pacific SIDS, the marked decline of the indicator $(-15.1 \%)$ may be a sign of difficulty with the use of their new CDMSs. The 2010 questionnaire (see Section 5 above) about CDMS status should give more reliable answers about these specific groups, but also for all WMO members. It should also confirm or invalidate the relevance of this indicator.

\section{CONCLUSIONS}

\subsection{Developing countries are still in the process of new-CDMS implementation}

The installation of new CDMSs initiated by WMO is relatively recent, beginning as it did in 2003. In developing countries, 71 NMHSs (53\% of all developing countries) are implementing a new CDMS (CLIMSOFT, CLIDATA, CLISYS, CLDB, CLIWARE, or JCDMS). But 21 developing-country NMHSs (16\% of all developing countries) are still using CLICOM and

Table 3. Evolution of the percentage of CLIMAT messages received in correct format by the Global Climate Observing System Surface Network Monitoring Centre between 2 periods for 4 groups of developing countries. Change: 2006-2008 minus 2000-2002

\begin{tabular}{|lccc|}
\hline Group & $\begin{array}{r}\text { Messages in correct format (\%) } \\
\text { 2000-2002 }\end{array}$ & $\begin{array}{c}\text { 2006-2008 } \\
(\%)\end{array}$ \\
\hline 1: Africa (with AGRHYMET) & 19.4 & 23.6 & +4.2 \\
2: Africa (not with AGRHYMET) & 2.4 & 8.3 & +5.9 \\
3: Caribbean & 13.5 & 18.9 & +5.4 \\
4: Pacific & 28.3 & 13.2 & -15.1 \\
\hline
\end{tabular}


will have to migrate to a new CDMS. It is very probable that a higher percentage of NMHSs would need to migrate, considering the cases of 'unknown' (26 NMHSs) and 'locally developed' (15 NMHSs) situations.

\subsection{Implementation evaluation}

The number of CDMS installations can be counted, but the implementation of CDMSs, i.e. their 'in-service' status and capacity to answer the needs of NMHSs, is difficult to assess. The attempt proposed here with the analysis of CLIMAT message reception based on 4 different groups and 45 NMHSs shows improvement for some NMHSs and a drop for others. A better view of CDMS status is expected in 2011 with the results of a questionnaire initiated by $\mathrm{CCl}$, which should identify potential problems and areas where more assistance is required.

Acknowledgements. This study is adapted from one we presented at the WMO Technical Conference on Changing Climate and Demands for Climate Services for Sustainable Development, Antalya, Turkey, 16-18 February 2010.

\section{LITERATURE CITED}

WMO (1989) Report of meeting of CLICOM experts. WCDP9, WMO-TD No. 342. WMO, Geneva

WMO (1997) Expert meeting to review and assess the Oraclebased prototype for future climate database management system. WMO-TD No. 902. WMO, Geneva

WMO (1998) Meeting of the WMO commission for climatology $(\mathrm{CCl})$ task group on a future WMO climate database management system. WMO-TD No. 932, WMO, Geneva

Submitted: October 4, 2010; Accepted: October 20, 2010
WMO (1999) Follow-up workshop to the WMO CCl task group meeting on a future WMO CDMS. WMO-TD No. 932. WMO, Geneva

WMO (2000a) Meeting of the WMO CCl task group on future WMO climate database management systems. WMO-TD No. 1025. WMO, Geneva

WMO (2000b) Training seminar on climate data management focusing on CLICOM/CLIPS development and evaluation (Niamey, Niger, 3 May-10 July 1999). WMO-TD No. 973. WMO, Geneva

WMO (2002) Report of the climate database management systems evaluation workshop. WMO-TD No. 1130. WMO, Geneva

WMO (2003) Informal planning meeting on the Voluntary Cooperation and related Technical Cooperation Programme. WMO, Geneva

WMO (2004) Informal planning meeting on the voluntary cooperation programme (VCP) and related technical cooperation activities, final report. WMO, Geneva

WMO (2005) Informal planning meeting on the voluntary cooperation programme (VCP) and related technical cooperation activities, final report. WMO, Geneva

WMO (2006a) Meeting of the CCl Expert Team on climate data management including metadata (November 2006 in Nairobi). WMO, Geneva

WMO (2006b) Informal planning meeting on the voluntary cooperation programme (VCP) and related technical cooperation activities, final report. WMO, Geneva

WMO (2007) Informal planning meeting on the voluntary cooperation programme (VCP) and related technical cooperation activities, final report. WMO, Geneva

WMO (2008) Informal planning meeting on the voluntary cooperation programme (VCP) and related technical cooperation activities, final report. WMO, Geneva

WMO (2009a) Meeting of the CCl Expert Team on climate data management including metadata (March 2009 in Toulouse). WMO, Geneva

WMO (2009b) Meeting of the CCl Expert Team on climate data management including metadata (November 2009 in Casablanca). WMO, Geneva

Proofs received from author(s): March 17, 2011 